\title{
Clinical and economic impact of a one-year treatment with omalizumab in patients with severe allergic asthma within a drug programme in Poland
}

\author{
Karina Jahnz-Różyk1, Joanna Lis ${ }^{2}$, Marta Warchoł ${ }^{1}$ and Aleksandra Kucharczyk ${ }^{*^{*}}$ (1)
}

\begin{abstract}
Background: Allergic asthma is the most prevalent phenotype of severe asthma where treatment with omalizumab (OMB) has been proven to be particularly beneficial. In Poland, OMB therapy is available and reimbursed within a drug programme where strict inclusion and exclusion criteria are defined.

The objective of this study was to present a descriptive analysis regarding the trends in outcomes (clinical, quality of life, costs) among a cohort of patients who satisfy inclusion criteria for the initiation of OMB treatment and who successfully responded to OMB according to a set of objective criteria.

Methods: A retrospective analysis of data collected during the 52 weeks of OMB treatment was carried out. The study population was adolescents and adults with severe allergic asthma that was uncontrolled despite a combination of high-dose inhaled corticosteroids (ICS)/long-acting beta-agonists (LABA) and/or other controllers (leukotriene receptor antagonists (LTRA), sustained-release theophylline, and short- or long-acting muscarinic antagonists (SAMA/LAMA), who were the first to finish the one-year treatment. A clinical and cost analysis for patients included in the programme was conducted comparing the one-year pre-treatment period to the one-year treatment period outcomes.

Results: Data of 85 patients who completed the first year of therapy were reviewed and analysed. Add-on OMB treatment resulted in a median decrease in exacerbation rate of $66 \%$ relative to the baseline and a reduction in oral steroid (OCS) dose by an average of $7.7 \mathrm{mg}$. At the end of the 52 weeks of therapy the changes in the quality of life questionnaire (AQLQ) and the asthma control questionnaire (ACQ) scores were 1.86 and 1.45 points, respectively. The mean cost of asthma treatment increased by an average of 15,979 EUR per patient per year (baseline period - 802 EUR/patient/year; OMB treatment - 16,781 EUR/patient/year). The cost to avoid one exacerbation was 17721 EUR.

Conclusion: The clinical outcomes for the observed subset of patients were highly improved. At the same time, costs of the treatment increased, mainly due to the high OMB costs. Other costs associated with a lower number of hospitalizations and ED and office visits and a reduction in OCS dose decreased. These descriptive data can be used for further investigation in defining patients who benefit the most from OMB treatment in clinical practice.
\end{abstract}

Keywords: Severe asthma, Omalizumab, Drug programmes in health care system in Poland, Cost of treatment

\footnotetext{
* Correspondence: olakucharczyk@gmail.com

${ }^{1}$ Department of Internal Diseases, Pneumonology, Allergology and Clinical

Immunology, Military Institute of Medicine, Szaserów 128, 04-141 Warsaw,

Poland

Full list of author information is available at the end of the article
} 


\section{Background}

Although severe asthma applies to only 5 to $10 \%$ of patients with asthma, a substantial portion of the health care costs is associated with this phenotype of the disease [1-3]. Only a small part of the cost is a result of diagnostic tests, which must be performed to differentiate severe asthma from other chronic diseases and to assess the impact of other diseases on the course of asthma. The greatest expenses are associated with treatment - an inadequate response to therapy, an inability to achieve sound asthma control and an increased risk of exacerbation - all of which result in additional high costs that affect health care utilization (HCU).

With the emergence of new data on the pathogenesis of asthma, the diversity of clinical presentations and the response to treatment, it is increasingly believed that severe asthma is a heterogeneous disease comprising discrete phenotypes that differ in pathogenesis, genetic background and clinical outcome $[4,5]$. One of the phenotypes is allergic asthma.

$\mathrm{OMB}$ is a recombinant humanized monoclonal antiIgE antibody designed to treat IgE-mediated disease by reducing the plasma concentration of free IgE antibodies. The efficacy and safety of OMB in severe persistent allergic asthma have been confirmed in numerous multicentre clinical trials $[6,7]$ where OMB as an addon therapy reduced the number of asthma exacerbations and concomitant medication burden and improved symptom severity and quality of life (QoL) compared to the use of standard therapy alone.

The Global Initiative for Asthma (GINA) guidelines [8] recommended that $\mathrm{OMB}$ be considered an adjunctive therapy for patients with moderate or severe allergic asthma that is uncontrolled on step 4 of treatment. Per GINA, a stepwise approach is needed for adjusting asthma treatment to achieve good symptom control and minimize the future risk of exacerbations, fixed airflow limitation and medication side-effects. The choice of therapy may, however, be affected by the cost of treatment.

Innovative therapies (primarily biological therapies) in Poland are reimbursed within drug programmes [9]. A drug programme is "guaranteed compensation, including therapies with innovative, expensive active substances which are not financed by other guaranteed benefits. The treatment is carried out in selected disease entities and includes a strictly defined group of patients". The advantage of carrying out treatment within drug programmes is more detailed qualification of patients recruited for treatment, based on well-described inclusion and exclusion criteria [10]. Check points allow, in turn, for a more detailed assessment of the efficacy, safety, and cost of the therapy.

Patients suffering from severe allergic asthma in Poland are treated within the drug program "Treatment of allergic, IgE-mediated asthma with omalizumab" [10]. This study evaluated the clinical outcomes and costs of add-on OMB therapy for severe allergic asthma in Poland based on a group of 85 patients who were the first to finish the one-year treatment.

\section{Methods \\ Study design and data dources}

The Drug Program Registry is a multi-centre, singlearm, open-label, observational registry. Patients with a diagnosis of severe IgE-dependent allergic asthma who met the inclusion and did not meet any of the exclusion criteria of the Polish Drug Program (Table 1) and who were treated with OMB for one year (in 2013 and 2014) at 36 centres in Poland were eligible for the assessment. Patients were recruited for the study using an electronic database, which is owned by the Polish Ministry of Health. The authors obtained the written consent of the Ministry for the use of the data, in accordance with regulations for the publication of patient data. The analysis included all patients subsequently entering this registry. All of them provided informed consent before each OMB administration.

\section{Patient population}

At the time of the analysis, there were 199 patients in the database (Fig. 1).

The criteria for the selection of patients for treatment with OMB (inclusion and exclusion criteria), drug dosing, laboratory tests necessary for qualifying, and a description of the control visits (to monitor the effectiveness and safety of treatment) can be found in the description of the programme (Annex B.44 [10]).

Baseline information on age, sex, asthma status, asthma control, exacerbations, average OCS dose (6 months prior to OMB treatment), tIgE, weight, FEV1, allergy confirmation tests, status of comorbidities, lung function, asthma control and concomitant medications, so as HCU in the year before the beginning of treatment, was collected in an electronic registry. Treatment monitoring visits occurred after 16 and 52 weeks after switching therapy. Patient evaluations included physical examination, spirometry, and response to treatment (Global Evaluation of Treatment Effectiveness - GETE) [5]. Assessment also covered asthma control (based on ACQ scoring) and quality of life (based on miniAQLQ scoring) $[11,12]$. Only patients whose GETE was excellent (complete control of asthma) or good (marked improvement) and whose ACQ and miniAQLQ results improved by more than 0.5 points, as well as those whose asthma exacerbations rates were not higher than in the year before therapy, could continue OMB treatment (responders). Other assessments included lung function (FEV1), asthma-related HCU and oral corticosteroid use. 
Table 1 Inclusion and exclusion criteria in Polish drug programme with $\mathrm{OMB}$

\begin{tabular}{|c|c|}
\hline \\
\hline \multicolumn{2}{|c|}{$\frac{\text { nclusion Criteria }}{\text { Adult and ad }}$} \\
\hline 2 & $\begin{array}{l}\text { dipropionate (CFC) per day or equivalent) in combination with a } \\
\text { second controller (i.e. LABA, LTRA, theophylline) }\end{array}$ \\
\hline 3 & \multirow{2}{*}{$\begin{array}{l}\text { Frequent use of OCS in the past, including the last } 6 \text { months } \\
\text { Total serum lgE levels } 30-1500 \mathrm{IU} / \mathrm{ml}\end{array}$} \\
\hline 4 & \\
\hline 5 & $\begin{array}{l}\text { Unequivocal in vitro reactivity to a perennial allergen in patients } \\
\text { with total serum lgE (tlgE) levels below } 76 \mathrm{IU} / \mathrm{ml}\end{array}$ \\
\hline 6 & $\begin{array}{l}\text { The fulfilment of at least three of the following criteria: } \\
\text { a) Uncontrolled asthma symptoms (lack of asthma control in } \\
\text { ACQ }>1.5 \text { points) } \\
\text { b) Three or more episodes of exacerbations a year requiring } \\
\text { systemic corticosteroids or increase their current dose. } \\
\text { c) Hospitalization in the past } 12 \text { months due to asthma exacerbation } \\
\text { d) Near fatal asthma episode in the past } \\
\text { e) Persistent airflow limitation (forced expiratory flow in one second } \\
\text { (FEV1) }<60 \% \text { predicted of normal or daily variability of peak } \\
\text { expiratory flow (PEF) }>30 \% \text { ) }\end{array}$ \\
\hline 7 & Weight $20-150 \mathrm{~kg}$ \\
\hline 8 & Non-smoker \\
\hline 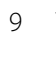 & $\begin{array}{l}\text { The exclusion of other than allergic reactions to inhaled perennial } \\
\text { allergens reasons causing severe asthma }\end{array}$ \\
\hline 10 & Exclusion criteria \\
\hline \multirow[t]{2}{*}{11} & $\begin{array}{l}\text { Exacerbations during treatment with } \mathrm{OMB} \text { if the number is equal } \\
\text { to or greater than in the period prior to the treatment year }\end{array}$ \\
\hline & $\begin{array}{l}\text { Criteria of efficacy not met: } \\
\text { a) Response to therapy in GETE less than excellent (complete } \\
\text { control of asthma)/good (marked improvement) } \\
\text { b) Meeting } 2 \text { of the following } 3 \text { criteria: } \\
\text { - Insufficient improvement in asthma control based on ACQ } \\
\text { (change in ACQ score less than or equal to } 0.5 \text { points) } \\
\text { - Insufficient improvement of the quality of life based on AQLQ } \\
\text { or mini AQLQ (change in AQLQ score less than or equal to } 0.5 \\
\text { points) } \\
\text { - OCS dose reduction of less than or equal } 5 \mathrm{mg} \text { (only patients } \\
\text { treated with OCS before enrolment) }\end{array}$ \\
\hline 12 & \\
\hline 13 & Noncompliance or poor adherence \\
\hline 14 & $\begin{array}{l}\text { Initiation of therapy with immunosuppressive drugs, anticancer, } \\
\text { infusions of immunoglobulins or other biological agents }\end{array}$ \\
\hline 15 & The occurrence of any contraindications to the use of OMB \\
\hline \multicolumn{2}{|r|}{6 Pregnant or breastfeeding woman } \\
\hline
\end{tabular}

Additionally, prior to each OMB administration, asthma control was assessed, and physical examination, vital signs and spirometry were performed as the patients completed questionnaires (ACQ and miniAQLQ).

\section{Outcomes measure}

The analysis of 85 patients who first completed 52 weeks of treatment with $\mathrm{OMB}$ was performed with detailed evaluation of the following outcomes:
1. Global Evaluation of Treatment Effectiveness (GETE) [5]

2. OCS dose

3. Asthma control (based on ACQ score)

4. Quality of life (based on miniAQLQ score)

5. Asthma exacerbations (total number of exacerbations including hospitalizations, physician office visits and ED visits due to asthma)

The analysis of clinical outcomes assumed that the patients are responders only if they meet all the following criteria: improvement in quality of life (an increase of greater than 0.5 points in the miniAQLQ score) and asthma control (decrease of greater than 0.5 points in the ACQ score), good or excellent asthma control in GETE and OCS dose reduction not less than $5 \mathrm{mg}$ per day (only patients treated with OCS before enrolment).

\section{Costs}

The cost analysis included the costs of OMB, unscheduled physician visits, emergency department (ED) visits and hospitalizations due to asthma.

The wholesale acquisition cost (WAC) was used for OMB and was 374 (2014 EUR) for one 150-mg vial. The annual cost of treatment with OMB was estimated based on the weight and IgE levels of the patients included. The average dose of OMB was $6645 \mathrm{mg}$ per patient per year, which means that mean annual cost of OMB treatment was 16,565 (2014 EUR).

The cost of exacerbations also included the cost of a physician visit, ED visit and hospitalization, which was based on the average reimbursement of health care resources in Poland, as determined by the public payer (NHF - National Health Fund). The costs of a physician visit, an ED visit and hospitalization due to asthma were 8.4 EUR, 719.42 EUR and 611.0 EUR, respectively. A sensitivity analysis of successful treatment was performed by calculating the costs to achieve a 0,5 -point increase in the AQLQ score, a 0,5-point decrease in the ACQ score and a 5-mg decrease in OCS dose.

\section{Statistical analysis of the study outcomes}

General characteristics of the study population, including the percentage of patients who have experienced specific changes in examined end points, were analysed using methods of descriptive statistics. Changes in normally distributed data were analysed using Student's t-test. Changes in non-normally distributed data were analysed using the Wilcoxon test. All comparisons were two-sided.

In the response to treatment analysis, OCS dose, AQLQ score and ACQ score during visits at week 0, week 16 and week 52 were compared. The Wilcoxon test analysed the reduction in OCS dose. Changes in 


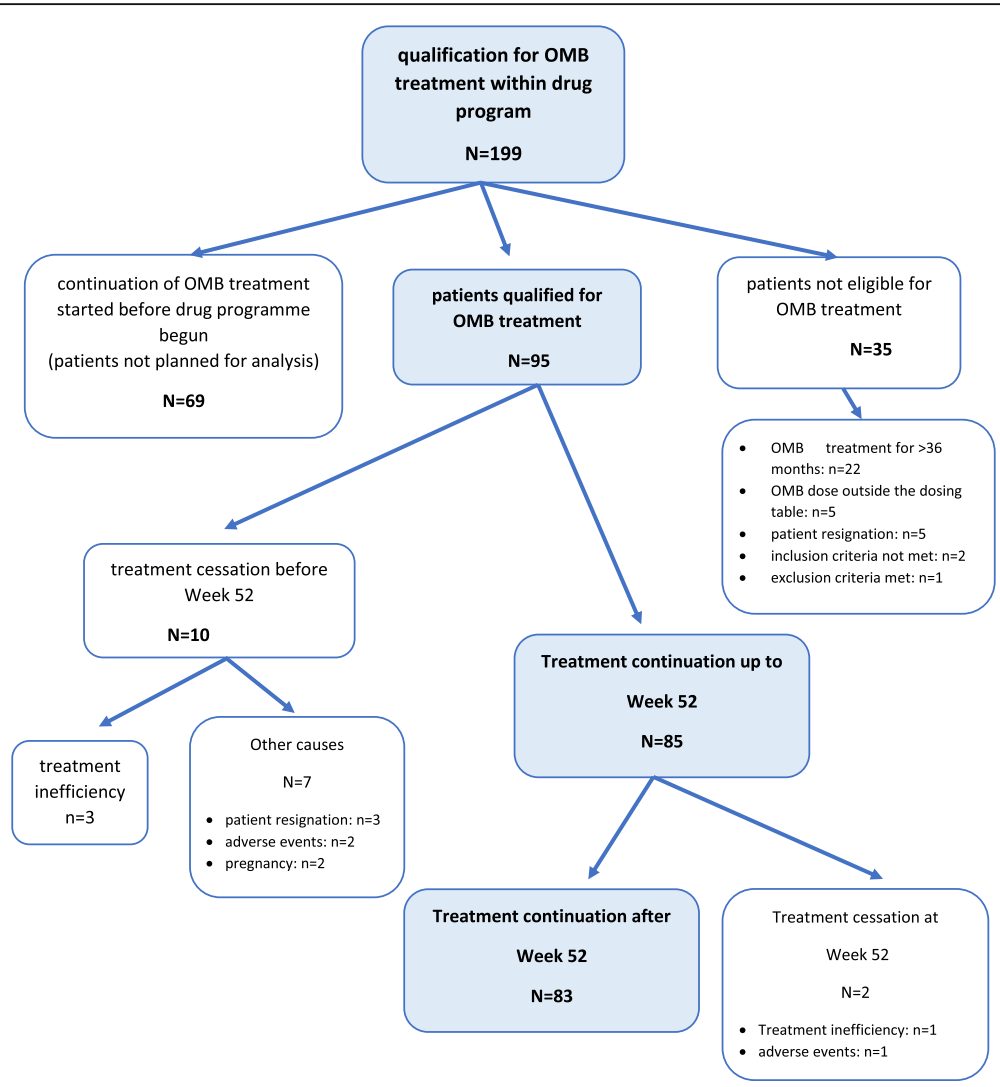

Fig. 1 Cohort construction flowchart. From 19.03.2013 to 01.07.2013, 199 applications were submitted to the drug programme. The analysis included a total of 95 patients - only those who initiated therapy with OMB. Sixty-nine patients who had previously received OMB and continued treatment were excluded, as were patients who, for various reasons, were not eligible for this therapy (35 patients). The most common cause of non-eligibility was prior treatment with OMB for a period longer than 36 months (22 patients), as it was initially assumed that the duration of treatment should not exceed 3 years. This was subsequently changed, and now the physician, based on clinical data, decides on the cessation of treatment. The other cause was an inability to determine the dose of the drug by serum total $\lg E$ level $(\mathrm{IU} / \mathrm{mL})$ measured before the start of treatment and by body weight $(\mathrm{kg})$. Five patients were outside the dosing table, and 2 patients did not meet inclusion criteria; one of them was not allergic, and the other had a tlgE greater than $1500(\mathrm{IU} / \mathrm{mL})$. Five patients resigned prior to the first dose. Of the 95 patients who started OMB treatment, ten discontinued this therapy before Week 52 (second monitoring point), three of them due to treatment failure observed in Week 16 (first monitoring visit). For the other patients, the treatment was discontinued for reasons such as pregnancy, withdrawal of consent for treatment, and adverse reactions. A group of 85 patients continued the treatment until Week 52, at which time they were evaluated for efficacy and safety. Therapy was then continued in 83 of these patients. Two patients were excluded at this point due to lack of efficacy (one patient) and side effects in the form of generalized erythematous oedema lesions (one patient)

AQLQ and ACQ were verified by t-test for paired observations. Analysis of asthma exacerbations before and during $\mathrm{OMB}$ treatment was performed with the Wilcoxon test.

An alpha level equal to $0.05 / \mathrm{N}$, where $\mathrm{N}$ is the number of post hoc tests performed (according to the Bonferroni correction), was used in the analysis.

Calculations were performed using Statistica 7.1 (StatSoft, Inc).

\section{Results}

\section{Demographics}

A summary of demographic characteristics is reported in Table 2. Thirty eight percent of the patients were male, and $100 \%$ were white. The average age was 44.9 years. The average total IgE concentration was
Table 2 Baseline demographic characteristics

\begin{tabular}{llll}
\hline Characteristic & mean & median & range \\
\hline Age, $y$ & 44.90 & 47.00 & $13-79$ \\
Sex (M/F), $\mathrm{n}$ & $33 / 52$ & & \\
Weight, $\mathrm{kg}$ & 77.40 & 74.00 & $34-140$ \\
Total IgE, IU/ml & 339.00 & 294.00 & $30-1300$ \\
Time since diagnosis of asthma, y & 23.98 & 22.00 & $4-66$ \\
FEV1, \% predicted at entry & 61.78 & 57.00 & $26-114$ \\
OCS dose, mg at entry & 12.59 & 10.00 & $5-40$ \\
ED visits past 12 mo, $\mathrm{n}$ & 0.67 & & $0-10$ \\
Hospital admissions past 12 mo, $\mathrm{n}$ & 1.11 & & $0-6$ \\
Exacerbation rate past 12 mo, $\mathrm{n}$ & 6.63 & & $1-30$ \\
ACQ at entry & 3.60 & 3.50 & $1.7-6$ \\
AQLQ at entry & 2.98 & 3.10 & $0-4.9$ \\
\hline
\end{tabular}


$339 \mathrm{IU} / \mathrm{ml}$ with a weight of $77.4 \mathrm{~kg}$, and the average dose of OMB counted per individual person, was $554 \mathrm{mg}$ per month. All patients were prescribed two or more asthma controller medications. The first evaluation was after 16 weeks, and the second after 52 weeks of treatment.

\section{Clinical outcomes analysis}

Most patients' response to treatment was good or excellent after 16 and 52 weeks of treatment (95.1 and 93.9\% respectively), while at the same time, there was a reduction in the OCS dose (on average by $7.7 \mathrm{mg}$ ) (Table 3). Compared with the baseline, the asthma exacerbation rate decreased by $66 \%$ during OMB treatment. Additionally, scores for quality of life questionnaires (AQLQ) and asthma control (ACQ) improved. All these changes were statistically significant $(p<0,000001)$.

\section{Cost analysis}

The mean asthma treatment cost during the OMB treatment of patients in the programme defined by inclusion and exclusion criteria was 16,781 EUR per patient per year compared with 802 EUR before the therapy.

This significant increase was mainly due to the high price of OMB, as the other costs of health care resources, including hospitalizations and ED and office visits, declined significantly after switching therapy to OMB (from 802 to 216 EUR in the annual assessment). The average annual exacerbation treatment cost is presented in Table 4.

Annual add-on treatment with OMB was also associated with the following:

- a reduction in mean OCS dose by $7.7 \mathrm{mg}$, wherein the cost of a one-unit decline amounted to 2067.1 EUR.
- an increase in the AQLQ score by 1.86 points, wherein the cost of one unit of growth amounted to 8607.2 EUR

- a reduction in the ACQ score by 1.5 points, wherein the cost of a one-unit decline amounted to $11,024.6$ EUR

- a reduction in the number of exacerbations of 4.38 per year. The cost of one exacerbation treated on an outpatient basis and in the hospital amounted to 5144.8 EUR and 12,576.2 EUR, respectively (Table 5 ).

\section{Discussion}

This paper presents the trends in clinical outcomes, quality of life and costs of a one-year treatment with $\mathrm{OMB}$ in patients with severe allergic asthma for a cohort of patients who satisfied the inclusion criteria for the initiation of $\mathrm{OMB}$ treatment and who successfully responded to $\mathrm{OMB}$ according to a set of objective criteria within a drug programme in Poland.

Drug programmes are one method of reimbursement, where patients are integrated into the treatment regimen of a clinical trial (inclusion and exclusion criteria) and then followed in daily practice.

Currently, 42 centres implement the drug programme. The treatment in the drug programme is carried out by physicians experienced in the diagnosis and treatment of severe persistent asthma and is 1restricted to patients prescribed systemic steroids (used chronically or during exacerbations) and for whom all other treatments have failed.

As shown in Poland, patients in this drug programme receive a significant clinical benefit from treatment with $\mathrm{OMB}$, resulting from a reduction in the number of asthma exacerbations, enhanced disease control and improved QoL. There was also a significant decrease in the

Table 3 Outcome measures $(n=85)$

\begin{tabular}{llll}
\hline Outcome measures & Week 0 & Week 16 & Week 52 \\
\hline OCS - Mean/Median & $12.59 / 10,00$ & $5.68 / 3.7$ & $4.86 / 2.5$ \\
Range & {$[5.00-40.00]$} & {$[0.00-40.00]$} & $p=0.00-40.00]$ \\
$p$ value & - & 4.000000 & $p=0.000000$ \\
AQLQ -Mean/Median & $2.98 / 3.10$ & {$[1.7-7.0]$} & $4.83 / 4.8$ \\
Range & {$[0.0-4.9]$} & $p=0.000000$ & {$[2.5-6.9]$} \\
$p$ value & - & $2.72 / 2.4$ & $p=0.000000$ \\
ACQ - Mean/ Median & $3.6 / 3.5$ & {$[0.4-2.7]$} & $2.15 / 2.10$ \\
Range & {$[1.7-6.0]$} & $p=0.004118$ & {$[0.1-5.7]$} \\
$p$ value & - & 2.98 & $p=0.000000$ \\
Asthma exacerbations - Mean & 6.63 & {$[0.0-19.5]$} & 1.93 \\
Range & {$[1.0-30.0]$} & $p=0.000000$ & {$[0.0-11.0]$} \\
$p$ value & - & $p=0.000000$ \\
\hline
\end{tabular}


Table 4 The average annual exacerbations treatment cost

\begin{tabular}{|c|c|c|c|c|c|c|c|c|c|}
\hline & \multirow{3}{*}{$\begin{array}{l}\text { Unit } \\
\text { Cost } \\
\text { (EUR) }\end{array}$} & \multicolumn{4}{|l|}{ At entry } & \multicolumn{4}{|l|}{ Week 52} \\
\hline & & \multicolumn{2}{|c|}{ Patients $(n=85)$} & \multicolumn{2}{|l|}{ Per patient } & \multicolumn{2}{|l|}{ Patients $(n=85)$} & \multicolumn{2}{|l|}{ Per patient } \\
\hline & & $\begin{array}{l}\text { No of } \\
\text { exacerbations }\end{array}$ & EUR & $\begin{array}{l}\text { No of } \\
\text { exacerbations }\end{array}$ & EUR & $\begin{array}{l}\text { No of } \\
\text { exacerbations }\end{array}$ & EUR & $\begin{array}{l}\text { No of } \\
\text { exacerbations }\end{array}$ & EUR \\
\hline Physician office visits & 8.4 & 421 & $14,735.00$ & 4.9529 & 173.35 & 157 & 5495.00 & 1.8471 & 64.65 \\
\hline $\begin{array}{l}\text { Hospitalizations in Intensive Care } \\
\text { Unit (ICU) }\end{array}$ & 719.4 & 11 & $12,679.59$ & 0.1294 & 149.17 & 0 & 0.00 & 0 & 0.00 \\
\hline ED visits & 719.4 & 57 & $65,703.33$ & 0.9706 & 772.98 & 13 & $14,984.97$ & 0.1529 & 176.29 \\
\hline Hospitalizations (all but ICU) & 611.0 & 75 & $191,100.00$ & 0.8824 & 2248.24 & 22 & $56,056.00$ & 0.2588 & 659.48 \\
\hline
\end{tabular}

dose of oral corticosteroids. No clinical improvement was observed in only $3.5 \%$ of the severe asthma patients.

Many studies have confirmed the real-world evidence (RWE) of OMB treatment [13-15].

The retrospective analysis of Barnes et al. [13] reported a lower number of exacerbations and enhanced QoL among British patients, consistent with previous studies of OMB. However, improved lung function and a reduction in annual steroid burden was greater in this study than in previous trials.

Findings from the 2-year eXpeRience registry agree with the results from randomized trials, indicating that OMB added to current therapy improves asthma control significantly among patients with uncontrolled persistent allergic asthma [14]. According to a physician's GETE, $69.9 \%$ of patients responded to OMB after 16 weeks. While the percentage of patients with no clinically significant exacerbations was $6.8 \%$ during the 12 -month pre-treatment period, this value increased to $54.1 \%$ at Month 12 and then to $67.3 \%$ at Month 24. Compared to the baseline, symptoms and the use of rescue medication decreased by $>50 \%$. Furthermore, maintenance OCS use decreased from $28.6 \%$ at the baseline to 16.1 and $14.2 \%$ at Months 12 and 24, respectively. Overall, OMB was deemed to have an acceptable safety profile. To summarize, the eXpeRience registry findings are consistent with the results of the clinical trials and suggest that OMB is associated with improved outcomes among patients with uncontrolled persistent allergic asthma. As shown in the Cochrane database published in 2014, $\mathrm{OMB}$ was effective in reducing the number of asthma exacerbations and hospitalizations when used with inhaled steroids, as well as during steroid tapering phases of clinical trials [15]. Moreover, OMB was proven to facilitate reducing or withdrawing inhaled steroids more effectively than a placebo.

There is no doubt that the biological treatment of chronic diseases is cost-intensive. Therefore, the decision of the payer and regulator to implement this therapy must be balanced in each country.

In Poland, the drug programme description (with inclusion and exclusion criteria) and final decision on entry into the drug programme is made by the Ministry of Health based on a previous assessment of HTA (in Poland, the Agency for Health Technology Assessment and Pricing - AOTMIT) and the opinion of the Economic Committee, which is involved in negotiating drug prices.

This analysis demonstrated the trends in the costs of treating severe asthma with OMB in Poland within a drug programme. The most cost-intensive occurrence is exacerbation treated in a hospital (12,576.2 EUR), followed by improvement in asthma control (11,024.6 EUR), improvement in QoL (8607.3 EUR), exacerbation treated on an outpatient basis (5144.8 EUR) and lowering the dose of systemic glucocorticosteroids (2067.3 EUR).

It should be emphasized that the analysis presented in this study concerns the direct cost of severe asthma patient treatment with $\mathrm{OMB}$ in the drug programme.

This descriptive analysis on the basis of data from the Patient Registry in Poland provides an estimation of costs and outcomes for the defined group of patients with severe asthma, which could be used for

Table 5 The mean change and the cost of the change

\begin{tabular}{|c|c|c|}
\hline \multicolumn{2}{|l|}{ The mean change at week 52 of OMB treatment } & \multirow{2}{*}{$\begin{array}{l}\text { The cost per unit change (EUR) } \\
-2067.3\end{array}$} \\
\hline OCS dose & $-7.72941(\mathrm{mg})$ & \\
\hline AQLQ scoring & 1.856471 (points) & -8607.3 \\
\hline ACQ scoring & -1.44941 (points) & $-11,024.6$ \\
\hline Number of physician office visits ${ }^{a}$ & -3.10588 & -5144.8 \\
\hline Number of hospitalizations ${ }^{a}$ & -1.27059 & $-12,576.2$ \\
\hline Total number of the physician office visits and hospitalizations ${ }^{a}$ & -4.37647 & -3651.2 \\
\hline
\end{tabular}

\footnotetext{
${ }^{a}$ only associated with asthma exacerbations
} 
the most advanced assessments of severe asthma treatment in Poland.

Unfortunately, the available data from this clearly defined cohort of patients in Poland do not allow one to calculate quality-adjusted life year (QALY) and the incremental cost-effectiveness ratio (ICER) as is recommended in pharmacoeconomic analyses.

There are numerous other publications that refer to QALY or ICER in this area [16-22].

An economic evaluation in a Spanish RWE study was performed from the societal perspective, including direct health costs (resource use and drug treatments) and indirect costs (disease impact on labour productivity) in 2016 Euros (16). When only direct costs were included, the incremental cost-effectiveness ratios (ICERs) were 1487.46 EUR per exacerbation avoided and 5425.13 EUR per 3point increase in ACT observed. When indirect costs were included, the ICERs were 1130.93 EUR per exacerbation avoided, and 4124.79 EUR per 3-point increase in ACT.

Campbell et al. concluded that adding OMB enhances quality-adjusted life years (QALY) while increasing direct medical costs. Their findings also indicated that using 16week assessments to guide decisions regarding long-term treatment improves cost-effectiveness [17]. Dal Negro et al. reported that $\mathrm{OMB}$ treatment, while improving health-related QoL, increases costs significantly [18].

Youji Oba et al. evaluated the cost-effectiveness of $\mathrm{OMB}$ in adults and adolescents with moderate to severe allergic asthma and concluded that from a pharmacoeconomic point of view, considering the high cost and modest efficacy, it would be more beneficial to use OMB in allergic asthmatic patients with poorly controlled symptoms. They emphasized that this therapy would result in a cost reduction only if used among non-smoking patients who were hospitalized 5 or more times or 20 days or longer per year despite using maximal asthma therapy [19].

Van Nooten and Wu et al. assessed OMB treatment to not be cost-effective and reported ICERs of 38.371 EUR and 821.000 USD respectively (ICERs were per QALY gained). Van Nooten et al. concluded that OMB treatment was cost-effective. Moreover, data from the reallife 1-year randomized open-label study (ETOPA) that used Canada as a reference country reported an ICER of 31.209 EUR among patients with severe persistent allergic asthma [20, 21].

The work of Devilde and Oba et al. indicated OMB treatment to be cost-effective when used in patients with severe allergic asthma. These results suggest that to determine the cost-effectiveness of OMB treatment, asthma severity and the risk of asthma exacerbations should be investigated $[19,22]$.

With a willingness-to-pay (WTP) of 45.000 USD per QALY, OMB treatment was also not cost-effective in adults in Japan, but OMB treatment will continue to be an available treatment option due to its mechanism of action and benefits for severe asthma patients, particularly responders [23]. The cost-effectiveness of OMB treatment may be improved by confining therapy to groups of previously predicted responders and decreasing the price. For paediatric patients in Japan, costeffectiveness is unclear and requires further study [24].

The interesting study of Faria et al. established the cost-effectiveness of OMB treatment under the list price and the Patient Access Scheme (PAS) discounted price for the UK National Health Service [25]. To assess the long-term cost-effectiveness of OMB treatment, a decision-analytics model was created. QALYs were used to measure the outcomes. Based on data from clinical trials, more specifically, previous hospitalization, maintenance OCS and three or more previous exacerbations, patient subgroups were created. The ICER costeffectiveness ratio ranged from 30.109 GBP to 57.557 GBP per QALY gained depending on the population considered while using the PAS price; however, incremental costeffectiveness ratios while using the list price were more than a third higher. The authors suggested that even though the cost-effectiveness of OMB treatment is more favourable under the PAS price, it only offers good value for the money when used in severe asthma patients and requires an optimistic outlook regarding asthma mortality and enhancing health-related QoL.

Recently published Canadian research has shown that OMB treatment was associated with higher costs (\$ 1796 Can.) but not with a reduction in clinically important outcomes [26]. The authors suggested that OMB treatment has limited effectiveness in this study population and that future studies should further explore subsets of patients most likely to benefit from OMB therapy.

Considering the high cost of OMB therapy, special attention should be paid to studies assessing the possibility of safe discontinuation of the therapy, prolongation of the intervals between subsequent injections or a reduction in the OMB dose $[27,28]$. The OMB dosing regimen should also be observed in real life for both clinical and economic assessment.

\section{Conclusions}

Because treatment with OMB in Poland is carried out in a framework of a drug programme, it is closely monitored, and the data are stored in a registry. Based on this registry, trends in clinical outcomes, quality of life and costs of treatments were assessed in a cohort of patients who satisfied the inclusion criteria for the initiation of $\mathrm{OMB}$ treatment and who successfully responded to OMB treatment according to a set of objective criteria. 
The clinical outcomes were highly improved. At the same time, the costs of treatment increased, mainly due to high OMB costs. Other costs associated with a decreased number of hospitalizations and ED and office visits and a reduction in OCS doses declined. It should be noted that even among patients who successfully respond to $\mathrm{OMB}$, the cost of therapy remain high and is far from being offset by the reduction in adverse clinical outcome.These descriptive data can be used to further investigate and define patients who benefit the most from OMB treatment in clinical practice.

\begin{abstract}
Abbreviations
ACQ: Asthma control questionnaire; AOTMIT: Agency for Health Technology Assessment; AQLQ: Asthma quality of life questionnaire; ED: Emergency Department; FEV1: Forced expiratory flow in one second; GETE: Global Evaluation of Treatment Effectiveness; GINA: Global Initiative for Asthma; HCU: Health care utilization; ICERs: Incremental cost-effectiveness ratios; ICS: Inhaled corticosteroids; LABA: Long-acting beta-agonists; LTRA: Leukotriene receptor antagonists; NHF: National Health Fund; OCS: Oral steroid; OMB: Omalizumab; PAS: Patient access scheme; QALY: Qualityadjusted life years; QoL: Quality of life; RWD: Real-world data; RWE: Realworld evidence; SAMA/LAMA: Short- or long-acting muscarinic antagonists; tlgE: Total IgE; WAC: Wholesale acquisition cost; WTP: Willingness-to-pay
\end{abstract}

\section{Acknowledgements}

Not applicable.

\section{Funding}

The study was funded by the Military Institute of Medicine (Warsaw, Poland). The authors declare that they have no competing interests.

\section{Availability of data and materials}

The dataset supporting the conclusions of this article is presented within the article. The detailed clinical dataset is not publically available to protect research subject privacy and confidentiality.

The data that support the findings of this study are available from the Polish Ministry of Health, but restrictions apply to the availability of these data, which were used under license for the current study and are not publicly available. Data are, however, available from the authors upon reasonable request and with the permission of Polish Ministry of Health.

\section{Authors' contributions}

KJR initiated the idea for the study and wrote the first draft interpreting the patient data regarding cost-effectiveness. JL completed the statistical analysis. MW built the database. AK completed a summary of all clinical information and prepared the final version of the paper. All authors reviewed and approved the final manuscript.

\section{Ethics approval and consent to participate}

A local ethics committee ruled that no formal ethics approval was required in this case.

\section{Consent for publication}

Not applicable.

\section{Competing interests}

The authors declare that they have no competing interests.

\section{Publisher's Note}

Springer Nature remains neutral with regard to jurisdictional claims in published maps and institutional affiliations.

\section{Author details}

'Department of Internal Diseases, Pneumonology, Allergology and Clinical Immunology, Military Institute of Medicine, Szaserów 128, 04-141 Warsaw, Poland. ${ }^{2}$ Sanofi-Aventis SP. z 0.o, Bonifraterska 17, 00-203 Warsaw, Poland.
Received: 12 February 2017 Accepted: 6 March 2018

Published online: 16 March 2018

\section{References}

1. Antonicelli L, Bucca C, Neri M, De Benedetto F, Sabbatani P, Bonifazi F, Eichler HG, Zhang Q, Yin DD. Asthma severity and medical resource utilization. Eur Respir J. 2004:23(5):723-9.

2. Accordini $S$, Corsico AG, Braggion M, et al. The cost of persistent asthma in Europe: an international population-based study in adults. Int Arch Allergy Immunol. 2013;160(1):93-101.

3. Godard P, Chanez P, Siraudin L, Nicoloyannis N, Duru G. Costs of asthma are correlated with severity. Eur Respir J. 2002;19(1):61-7.

4. Moore WC, Fitzpatrick AM, Li X, Hastie AT, Li H, Meyers DA, Bleecker ER. Clinical heterogeneity in the severe asthma research program. Ann Am Thorac Soc. 2013:10(Suppl):S118-24.

5. Bousquet J, Rabe K, Humbert M, Chung KF, Berger W, Fox H, et al. Predicting and evaluating response to omalizumab in patients with severe allergic asthma. Respir Med. 2007;101(7):1483-92.

6. Holgate ST, Chuchalin AG, Hébert J, Lötvall J, Persson GB, Chung KF, Bousquet J, Kerstjens HA, Fox H, Thirlwell J, Cioppa GD. Omalizumab 01 international study group. Efficacy and safety of a recombinant antiimmunoglobulin E antibody (omalizumab) in severe allergic asthma. Clin Exp Allergy. 2004;34(4):632-8

7. Humbert M, Beasley R, Ayres J, Slavin R, Hébert J, Bousquet J, Beeh K-M, Ramos S, Canonica GW, Hedgecock S, Fox H, Blogg M, Surrey K. Benefits of omalizumab as add on therapy in patients with severe persistent asthma who are inadequately controlled despite best available therapy (GINA 2002 step 4 treatment): INNOVATE. Allergy. 2005:60(3):309-16.

8. Raport Global Strategy for Asthma Management and Prevention - Revised 2016. http://www.ginasthma.org.

9. NOTICE OF THE MINISTER OF HEALTH of 26 October 2012 on the list of reimbursed drugs, foodstuffs intended for particular nutritional uses and medical devices at the date of 1 November 2012. Access: http://www.mz. gov.pl/leki/refundacja/lista-lekow-refundowanych-obwieszczenia-ministrazdrowia/obwieszczenie-ministra-zdrowia-z-dnia-26-pazdziernika-2012-r.

10. Annex B.44 to the Notice of the Minister of Health of 28 October 2015 on the list of reimbursed drugs, foodstuffs intended for particular nutritional uses and medical devices at the date of 1 November 2015. http://onkologia-online.pl/ upload/obwieszczenie/2012.10.26/44.pdf

11. Juniper EF, O'Byrne PM, Guyatt GH, Ferrie PJ, King DR. Development and validation of a questionnaire to measure asthma control. Eur Respir J. 1999;14(4):902-7.

12. Juniper EF, Guyatt HG, Epstein RS, Ferie PJ, Jaesche R, Hiller TK. Evaluation of impairment of health-related quality of life in asthma: development of a questionnaire for use in clinical trials. Thorax. 2002;47(2):76-83.

13. Barnes N, Menzies-Gow A, Mansur AH, Spencer D, Percival F, Radwan A Niven R. Effectiveness of Omalizumab in severe allergic asthma: a retrospective UK-real world study. J Asthma. 2013;50(5):529-36.

14. Braunstahl GJ, Chen CW, Maykut R, Georgiou P, Peachey G, Bruce J. The eXpeRience registry: the 'real-world' effectiveness of omalizumab in allergic asthma. Resp Med. 2013;107(8):1141-51.

15. Normansell R, Walker S, Milan SJ, Walters EH, Nair P. Omalizumab for asthma in adults and children. Cochrane Database Syst Rev. 2014;1:CD003559. https://doi.org/10.1002/14651858.CD003559.pub4.

16. Vennera MD, Valero A, Uría E, Forné C, Picado C. Cost-effectiveness analysis of omalizumab for the treatment of severe persistent asthma in real clinical practice in Spain. Clin Drug Investig. 2016;26(7):567-78.

17. Campbell JD, Spackman DE, Sullivan SD. The costs and consequences of omalizumab in uncontrolled asthma from a USA payer perspective. Allergy. 2010;65(9):1141-8

18. Dal Negro RW, Pradelli L, Tognella S, Micheletto C, Iannazzo S. Cost-utility of add-on omalizumab in difficult-to-treat allergic asthma in Italy. Eur Ann Allergy Clin Immunol. 2011;43(2):45-53.

19. Oba Y, Salzman GA. Cost-effectiveness analysis of omalizumab in adults and adolescents with moderate-to-severe allergic asthma. J Allergy Clin Immunol. 2004;114(2):265-9.

20. van Nooten F, Stern S, Braunstahl GJ, Thompson C, Groot M, Brown RE. Cost-effectiveness of omalizumab for uncontrolled allergic asthma in the Netherlands. J Med Econ. 2016;16(3):342-8. 
21. Wu AC, Paltiel AD, Kuntz KM, Weiss ST, Fuhlbrigge AL. Cost-effectiveness of omalizumab in adults with severe asthma: results from the asthma policy model. J Allergy Clin Immunol. 2007;120(5):1146-52.

22. Dewilde S, Turk F, Tambour M, Sandström T. The economic value of anti-lgE in severe persistent, IgE-mediated (allergic) asthma patients: adaptation of INNOVATE to Sweden. Curr Med Res Opin. 2006;22(9):1765-76.

23. Morishima T, Ikai H, Imanaka Y. Cost-effectiveness analysis of omalizumab for the treatment of severe asthma in japan and the value of responder prediction methods based on a multinational trial. Value Health Reg Iss. 2013;2(1):29-36.

24. Yoshikawa H, Iwata M, Matsuzaki H, Ono R, Murakami Y, Taba N, Honjo S, Motomura C, Odajima H. Impact of omalizumab on medical cost of childhood asthma in Japan. Pediatr Int. 2016;58(5):425-8. https://doi.org/10. 1111/ped.12936.

25. Faria R, McKenna C, Palmer S. Optimizing the position and use of omalizumab for severe persistent allergic asthma using cost-effectiveness analysis. Value Health. 2014;17(8):772-82.

26. Tadrous M, Khuu W, Lebovic G, Stanbrook MB, Martins D, Paterson JM, Mamdani MM, Juurlink DN, Gomes T. Real-world health care utilization and effectiveness of omalizumab for the treatment of severe asthma. Ann Allergy Asthma Immunol. 2017; https://doi.org/10.1016/j.anai.2017.08.016.

27. Domingo C, Pomares X, Navarro A, Amengual MJ, Montón C, Sogo A Mirapeix RM. A step-down protocol for omalizumab treatment in oral corticosteroid-dependent allergic asthma patients. Br I Clin Pharmacol. 2017. https://doi.org/10.1111/bcp.13453.

28. Vennera MDC, Sabadell C, Picado C, Spanish Omalizumab Registry. Duration of the efficacy of omalizumab after treatment discontinuation in 'real life' severe asthma. Thorax. 2017. https://doi.org/10.1136/thoraxjnl-2017-210017.

\section{Submit your next manuscript to BioMed Central and we will help you at every step:}

- We accept pre-submission inquiries

- Our selector tool helps you to find the most relevant journal

- We provide round the clock customer support

- Convenient online submission

- Thorough peer review

- Inclusion in PubMed and all major indexing services

- Maximum visibility for your research

Submit your manuscript at www.biomedcentral.com/submit

) Biomed Central 